\title{
Nova Scotia hospital buys bulletproof vests
}

Published at www.cmaj.ca on Jan. 18

$\mathrm{S}$ ecurity personnel at the IWK (Izaak Walton Killam) Health Centre in Halifax, Nova Scotia, will be sporting a new look this spring: bulletproof vests. The initiative is a first for a hospital in Nova Scotia.

The children's hospital has ordered 35 vests, which are also slash-proof, at a cost of $\$ 29000$. The decision to buy the vests wasn't taken lightly, says Allan Horsburgh, the centre's vicepresident and chief financial officer. It became easier late last year, however, after a young man was shot and wounded in the hospital's parking lot.

"If you can have a shooting in a children's hospital, anything can happen, anywhere, any time," says Horsburgh.

Police say the shooting wasn't random. It was likely related to ongoing drug wars in Halifax, and the victim just happened to be visiting someone at the centre when it occurred. Still, there is concern that it could happen again and that increased security measures were needed. Drug-related violence, after all, tends to be an enduring problem in many urban areas.

"I think it's only going to get worse," says Janet Hazelton, president of the Nova Scotia Nurses' Union, which represents nurses at the centre.

Most of the doctors, nurses and other staff at the centre, along with patients and their families, endorse the hospital's move to enhance security, says Horsburgh. Hospital management, however, was initially worried about how the facility might be perceived with a phalanx of security personnel walking the corridors in bulletproof vests. In the end, the shooting in the parking lot tipped the balance.

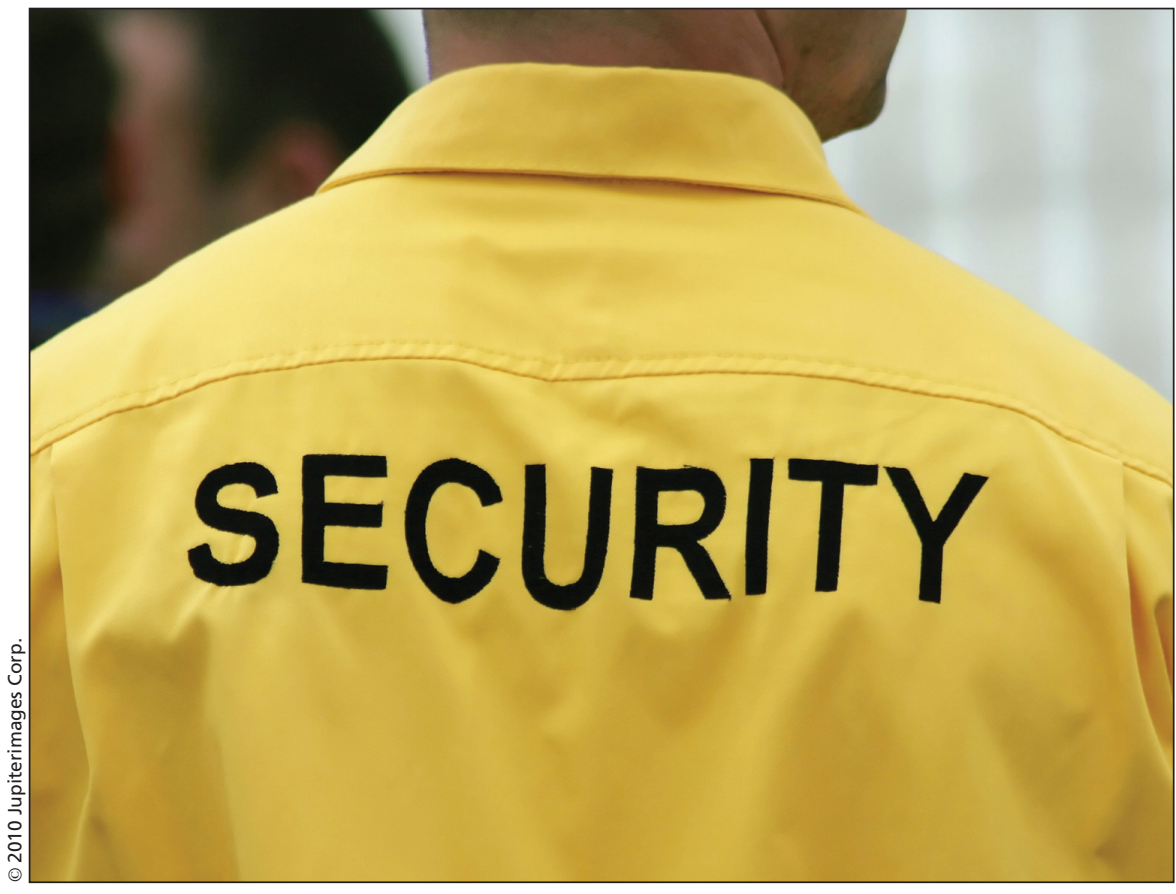

The IWK (Izaak Walton Killam) Health Centre in Halifax, Nova Scotia, has ordered 35 bulletproof vests for its security staff. Last year, a young man was shot in the hospital's parking lot.

The centre is not the only Canadian hospital attempting to improve security, though equipping security staff with bulletproof vests is not a universal practice. "Some hospitals are doing this," says Horsburgh. "Some don't even have security staff."

Only security staff is being fitted with bulletproof vests at the IWK Health Centre. The centre is not considering expanding the list of personnel who will wear bulletproof vests beyond security. They respond first to potentially dangerous incidents, says Horsburgh, so it makes sense that they be protected. It makes no sense, on the other hand, to equip health professionals with bulletproof vests, he says.
The vests might impede doctors and nurses from properly doing their jobs. The vests also might send a message to patients and families that no hospital would want to send: This is a dangerous place.

During contract negotiations, the nurses' union never pushed for bulletproof vests but the topic of protection for nurses is frequently discussed. The union has had no success in getting its security concerns addressed, according to Hazelton.

"Is this top of mind for nurses? I don't think so," says Hazelton. "Should it be? Yes." — donalee Moulton, Halifax, NS

DOI:10.1503/cmaj.109-3155 